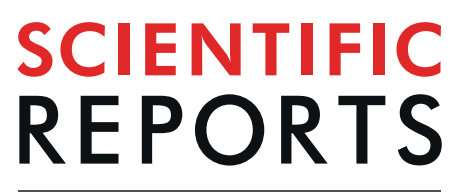

natureresearch

Received: 26 March 2019

Accepted: 18 July 2019

Published online: 01 August 2019

\section{Plant chemical genetics reveals colistin sulphate as a SA and NPR1-independent $P R 1$ inducer functioning via a p38-like kinase pathway}

\author{
Vivek Halder $\mathbb{1}^{1,2,3}$, Mohamed N. S. Suliman ${ }^{1,4}$, Farnusch Kaschani ${ }^{2} \&$ Markus Kaiser $^{2}$
}

In plants, low-dose of exogenous bacterial cyclic lipopeptides (CLPs) trigger transient membrane changes leading to activation of early and late defence responses. Here, a forward chemical genetics approach identifies colistin sulphate (CS) CLP as a novel plant defence inducer. CS uniquely triggers activation of the PATHOGENESIS-RELATED 1 (PR1) gene and resistance against Pseudomonas syringae pv. tomato DC3000 (Pst DC3000) in Arabidopsis thaliana (Arabidopsis) independently of the PR1 classical inducer, salicylic acid (SA) and the key SA-signalling protein, NON-EXPRESSOR OF PR1 (NPR1). Low bioactive concentration of CS does not trigger activation of early defence markers such as reactive oxygen species (ROS) and mitogen activated protein kinase (MAPK). However, it strongly suppresses primary root length elongation. Structure activity relationship (SAR) assays and mode-ofaction (MoA) studies show the acyl chain and activation of a $\sim 46 \mathrm{kDa}$ p38-like kinase pathway to be

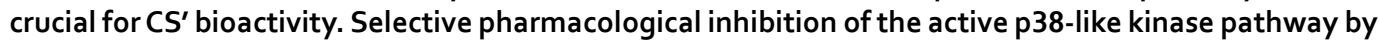
SB203580 reverses CS' effects on PR1 activation and root length suppression. Our results with CS as a chemical probe highlight the existence of a novel SA- and NPR1-independent branch of $P R 1$ activation functioning via a membrane-sensitive $p 38$-like kinase pathway.

In nature, plants are in a constant exposure to a plethora of harmful and beneficial microorganisms. Recognition of pathogenic molecular cues such as microbe-associated molecular patterns (MAMPs) or effector molecules results in MAMP-triggered immunity (MTI) or effector-triggered immunity (ETI), respectively ${ }^{1}$. These recognition events initiate a variety of early defence responses such as ROS production, MAPK activation as well as triggers downstream signalling mediated via phytohormones such as SA, jasmonic acid, and ethylene ${ }^{2}$. The small phenolic phytohormone SA plays a critical role in plant defence by inducing systemic acquired resistance (SAR) ${ }^{3}$. Pathogen attack triggers the expression of SA-biosynthetic gene ISOCHORISMATE SYNTHASE1 (ICS1) ${ }^{4}$ leading to an accumulation of SA which in turn is regulated by key regulators such as EDS $1^{5}$. SA is perceived by two proteins, NPR $1^{6}$ as well as the two NPR1 paralogs, NPR3 and NPR4 ${ }^{7}$. Increase in SA-levels monomerises NPR1 causing its translocation to the nucleus and subsequent expression of defence genes such as PR1.

An ability to modulate plant defence signalling processes in a spatio-temporal manner offers several advantages for crop protection ${ }^{8}$. Chemical genetics i.e. use of small bioactive chemicals as probes has now become an established approach to study plant biological responses. It has been applied to study a variety of phytohormones signalling networks, endomembrane trafficking as well as cell wall formation ${ }^{9,10}$. Chemical screenings have been instrumental in identifying SA-like defence inducing compounds ${ }^{11}$. Some well-characterised examples include: benzothiadiazole $(\mathrm{BTH})^{12}, 2,6$-dichloro-isonicotinic acid (INA) ${ }^{13}, 3,5$-dichloroanthranilic acid (DCA) ${ }^{14}$,

${ }^{1}$ Chemical Biology Laboratory, Max Planck Institute of Plant Breeding Research, Carl-von-Linnè-Weg 10, 50829, Köln, Germany. ${ }^{2}$ Chemical Biology, Centre of Medical Biotechnology, Faculty of Biology, University of DuisburgEssen, Universitätsstr. 2, 45141, Essen, Germany. ${ }^{3}$ Present address: Rijk Zwaan, De Lier, 2678 ZG, The Netherlands. ${ }^{4}$ Present address: Desert Research Centre, 11753 El matareya, Cairo, Egypt. Correspondence and requests for materials should be addressed to V.H. (email: v.halder@rijkzwaan.nl) or M.K. (email: markus.kaiser@uni-due.de) 
probenazole ${ }^{15}$, imprimatins ${ }^{16}$ etc., amongst others. All these chemicals induce canonical SA marker genes such as PR1 and require key SA-signalling components or SA itself for their bioactivity ${ }^{11}$.

In recent years, a number of CLPs such as surfactin, iturin, and fengycin etc., secreted by plant growth promoting rhizobacteria (PGPR), have been investigated for their defence-priming properties in plants. CLPs are natural products with wide structural diversity and strong antibiotic properties. They are synthesised by bacterial non-ribosomal peptide synthetases (NRPS) and share an overall similar architecture characterised by hydrophobic and acidic amino acids in their ring structure coupled to a fatty acid chain of variable length ${ }^{17}$. These compounds are now considered as a new class of MAMPs ${ }^{18-21}$ and are strong candidates for both biological pesticides and defence inducers ${ }^{22}$. Bioactive CLPs at low concentrations can sensitise plant lipid membranes leading to onset of early and late defence responses ${ }^{18,20,23}$. However, knowledge about associated signalling components and pathways is still in its infancy.

The polymyxin class of CLPs are strong antibiotics secreted by Paenibacillus polymyxa ${ }^{24}$. Typically, all polymyxins consist of a heptacyclopeptide fragment attached to a linear tripeptide with a fatty acid chain of varying length at the N-terminus and are polycationic via incorporation of the non-canonical diaminobutryic acid $(\mathrm{Dab})^{25}$. Polymyxin E (PmE) or CS is an FDA approved commercial antibiotic used against Gram-negative bacteria infections ${ }^{26}$. At high concentrations $\mathbf{C S}$ has a strong biosurfactant property; however, at low concentrations it can modulate a variety of other functions such as inhibiting prokaryotic $\mathrm{Hsp}^{2} 0^{27}$ and eukaryotic $\mathrm{Hsp} 70^{28} \mathrm{chaper-}$ one activities or inducing innate immunity in nematodes by targeting a p38 kinase ${ }^{29}$.

The p38 kinase is a well-established membrane osmosensor ${ }^{30}$ known to play key roles during oxidative stresses in animals ${ }^{31}$. Plants lack classical p38 kinases ${ }^{32}$; however, several plant studies have implicated the activation of a p38-like kinase pathway during osmotic stress ${ }^{33,34}, \mathrm{ABA}$-induced stomatal closure ${ }^{35}$, and cellular redox flux ${ }^{36}$. CS has been found to activate p38 kinase pathway in animal systems ${ }^{29,37}$, but its impact on plant p38-like kinase pathway is so far unknown.

In this study, we report on CS as a novel plant defence inducer. We identified CS through a phenotypic forward chemical genetic screen using PR1p::GUS defence reporter plants and a library of well-annotated commercial drugs of the Prestwick library. CS uniquely induces the SA-marker gene PR1 independently of both SA and NPR1 demonstrating its distinctness from many natural and synthetic plant defence inducers. Mode-of-action studies reveal CS does not require kinases involved in ROS or MAPK signalling rather, but works via an active $46 \mathrm{kDa}$ p38-like kinase pathway.

\section{Results}

CS is a novel activator of the PR1 defence gene in Arabidopsis. The $P R 1$ gene is a well-known defence marker strongly responsive to SA accumulation upon pathogen attack ${ }^{13}$. Accordingly, monitoring PR1 upregulation is an effective approach to identify potential plant defence activators ${ }^{11}$. Therefore, as a starting point to identify functional analogues of SA, we performed an in planta forward chemical genetic screen using the PCL (http://www.prestwickchemical.com/index.html) of 1280 small molecules (mostly approved drugs) along with 128 other handpicked compounds. We tested, in duplicates, $20 \mu \mathrm{M}$ of each chemical on 14-day-old PR1p::GUS ${ }^{38}$ seedlings grown hydroponically in a 96-well plate format under long day conditions. Incubation with $200 \mu \mathrm{M}$ SA or the solvent DMSO (1\%) served as internal controls and bioactivity of compounds on PR1p::GUS induction was scored via an in situ GUS assay ${ }^{39}$. The resulting GUS-activity was converted to Z-scores as a criterion for hit-selection (Fig. 1A). For a confident primary-hit selection, we set a stringent threshold of Z-score $\geq 4$ to focus on the strongest candidates with a bioactivity at least 4 times or higher than the DMSO control. In total, we identified six primary hits: acetyl salicylic acid (present twice in the chemical collection), 4-methyl umbelliferone, alexidine dihydrochloride, isradipine, and CS. About $80 \%$ of all tested compounds displayed a Z-score of around zero, indicating no effect on $P R 1$ induction.

All six primary hits were retained in the secondary screenings. However, we decided to proceed further with CS as (i) CS and other polymyxins such as polymyxin B (PmB) and polymyxin B nonapeptide $(\mathrm{PmBN})^{40}$ were commercially available (Fig. 1B), (ii) acetyl salicylic acid is a known SA-derivative ${ }^{41}$ and 4-methyl umbelliferone corresponded to the in situ GUS assay readout ${ }^{39}$, and therefore might well be an artefact (iii) CS displayed stronger bioactivity than alexidine dihydrochloride and isradipine, and (iv) unlike the other well-studied surfactin-type CLPs, CS polymyxins were never investigated in Arabidopsis before. To confirm the observed in planta effect of CS, we first performed a dose-response assay using 0.1 to $100 \mu \mathrm{M}$ CS (Fig. 1C). PR1p::GUS expression steadily increased in a dose-dependent manner until $10 \mu \mathrm{M}$ and declined sharply at $\geq 30 \mu \mathrm{M}$ indicating the onset of toxic effects. The resulting half maximal effective concentration $\left(\mathrm{EC}_{50}\right)$ of $\mathbf{C S}$ for $P R 1$ induction was $5 \mu \mathrm{M}$. Next, we validated CS' bioactivity, in vivo, by quantifying its effect on the accumulation of endogenous PR1 mRNA levels. Hydroponically grown 14-day-old Col-0 seedlings and soil-grown 28-day-old mature Col-0 plants were treated with $5 \mu \mathrm{M} \mathrm{CS}$ for $24 \mathrm{~h}$. In both cases, CS strongly triggered a robust increase of $P R 1$ transcripts compared to the DMSO controls (Fig. 1D). These results confirmed CS-mediated PR1 induction and also the robustness of our in situ GUS assays as a tool for chemical screenings. PR1p::GUS induction was detectable already after $30 \mathrm{~min}$ and steadily increased up to $24 \mathrm{~h}$ (Supplemental Fig. S1). Altogether, our results indicate that CS is a novel exogenous activator of the defence gene PR1 in Arabidopsis.

CS does not stress plants at its $\mathrm{EC}_{50}$ but affects seed germination and root growth. CS is a well-known biosurfactant courtesy of its cationic L-diamino-butyric acids (L-Dab) that interact with the anionic lipopolysaccharide molecules of Gram-negative bacteria to induce membrane disruption ${ }^{40}$. Plant membranes; however, have a different chemical composition than Gram-negative bacteria and hence certain CLPs such as surfactin are able to interact with plant membranes without inducing concomitant damage at low concentrations ${ }^{20,23}$. To test whether CS displays similar properties, we incubated Arabidopsis seedlings for $24 \mathrm{~h}$ with increasing concentrations of CS, followed by a subsequent Evans blue-based cell death quantification assay. In line with earlier 


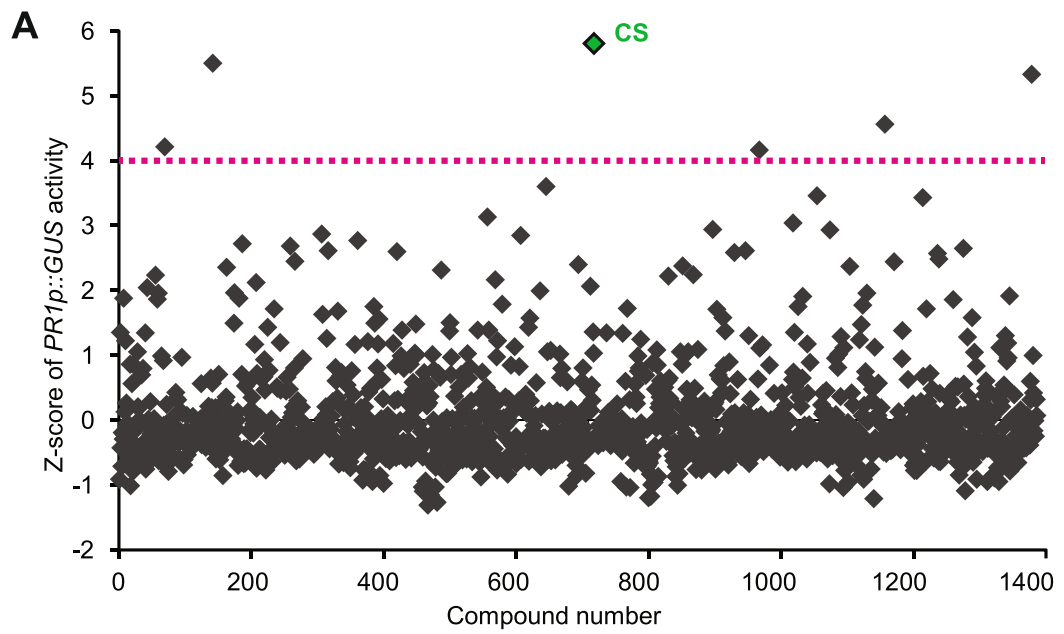

B

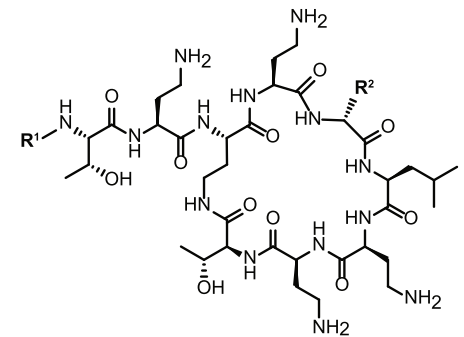

\begin{tabular}{|c|c|c|}
\hline & $\mathbf{R}^{1}$ & $\mathbf{R}^{2}$ \\
\hline$\underset{\text { (Colistin sulfate }}{\text { CS }}$ & & \\
\hline$\underset{\text { (Polymyxin B) }}{\text { PmB }}$ & & \\
\hline $\begin{array}{c}\mathrm{PmBN} \\
\text { (Polymyxin B } \\
\text { nonapeptide) }\end{array}$ & $\mathrm{Hz}$ & \\
\hline
\end{tabular}

C
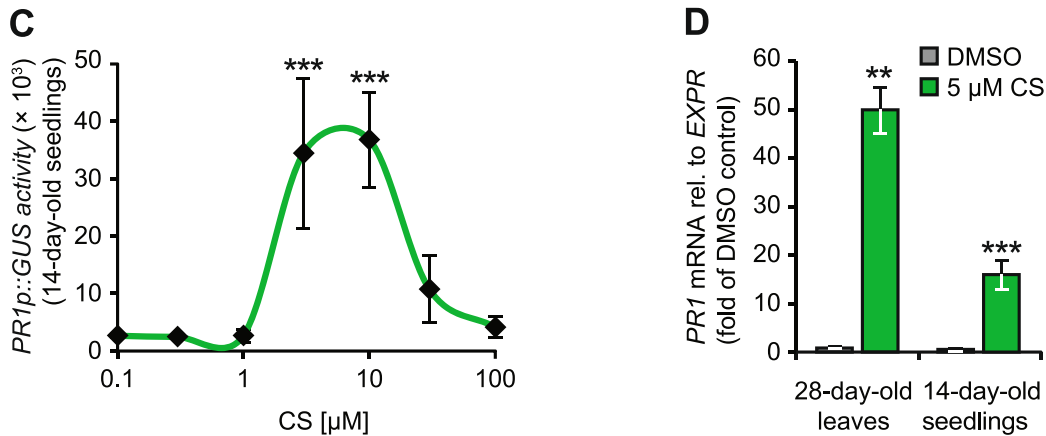

Figure 1. CS is a novel activator of the $P R 1$ defence gene in Arabidopsis. (A) Hydroponically grown (96well microtiter plate format) 14-day-old PR1p::GUS Arabidopsis reporter seedlings were treated in duplicate with the compounds from the chemical library $(20 \mu \mathrm{M})$ for $24 \mathrm{~h}$. GUS activity was recorded and converted to $\mathrm{Z}$-score values. Compounds above a Z-score of 4 (indicated by a magenta dotted line) were re-screened leading to the identification of CS (green diamond). (B) Chemical structure of $\mathbf{C S}$ and two related polymyxins: PmB and PmBN. (C) 14-day-old hydroponically grown PR1p::GUS reporter seedlings were treated with increasing concentrations of CS for $24 \mathrm{~h}$ before measuring GUS activity. (D) Leaves of 28-day-old and 14-day-old Col-0 plants were treated with DMSO (1\%) or CS $(5 \mu \mathrm{M})$ for $24 \mathrm{~h}$. PR1 transcript was quantified by qRT-PCR and normalised to the reference gene At4g26410 (Expressed Protein, EXPR). The values represent the mean $( \pm S D)$ of at least three biological replicates. All experiments were repeated at least twice with similar outputs. Asterisks indicate significant differences from control values $(* \mathrm{P}<0.05, * * \mathrm{P}<0.01$, and $* * * \mathrm{P}<0.001$, two-tailed Student's t-test).

reports for surfactin-type CLPs ${ }^{20,23}$, we observed cell toxicity only at $\geq 10 \mu \mathrm{M}$, indicating lower concentration of $5 \mu \mathrm{M}$ are well-tolerated in two-week-old seedlings (Fig. 2A). Next, to understand the long-term effect of CS on plant growth and development, we germinated Col-0 seeds hydroponically in presence of 0 to $100 \mu \mathrm{M} \mathrm{CS}$. A marked reduction in seed germination was noticed starting at $1 \mu \mathrm{M}$ with complete inhibition at $\geq 3 \mu \mathrm{M}$ (Fig. $2 \mathrm{~B}$ ). The seed germination assays showed a marked impact of $\mathbf{C S}$ on root emergence starting at concentrations of $1 \mu \mathrm{M}$. Upon further examination, we found that $0,0.1,0.5$, and $3 \mu \mathrm{M}$ CS impart a dose-dependent inhibitory effect on primary root growth elongation (Fig. 2C,D). Noticeably, a clear increase in root branching was observed upon application of CS (Fig. 2C), which strongly resemble the impact of its producer Paenibacillus polymyxa on its host root phenotype ${ }^{42}$. Furthermore, the impact of $\mathbf{C S}$ on root growth was independent of auxin signalling 

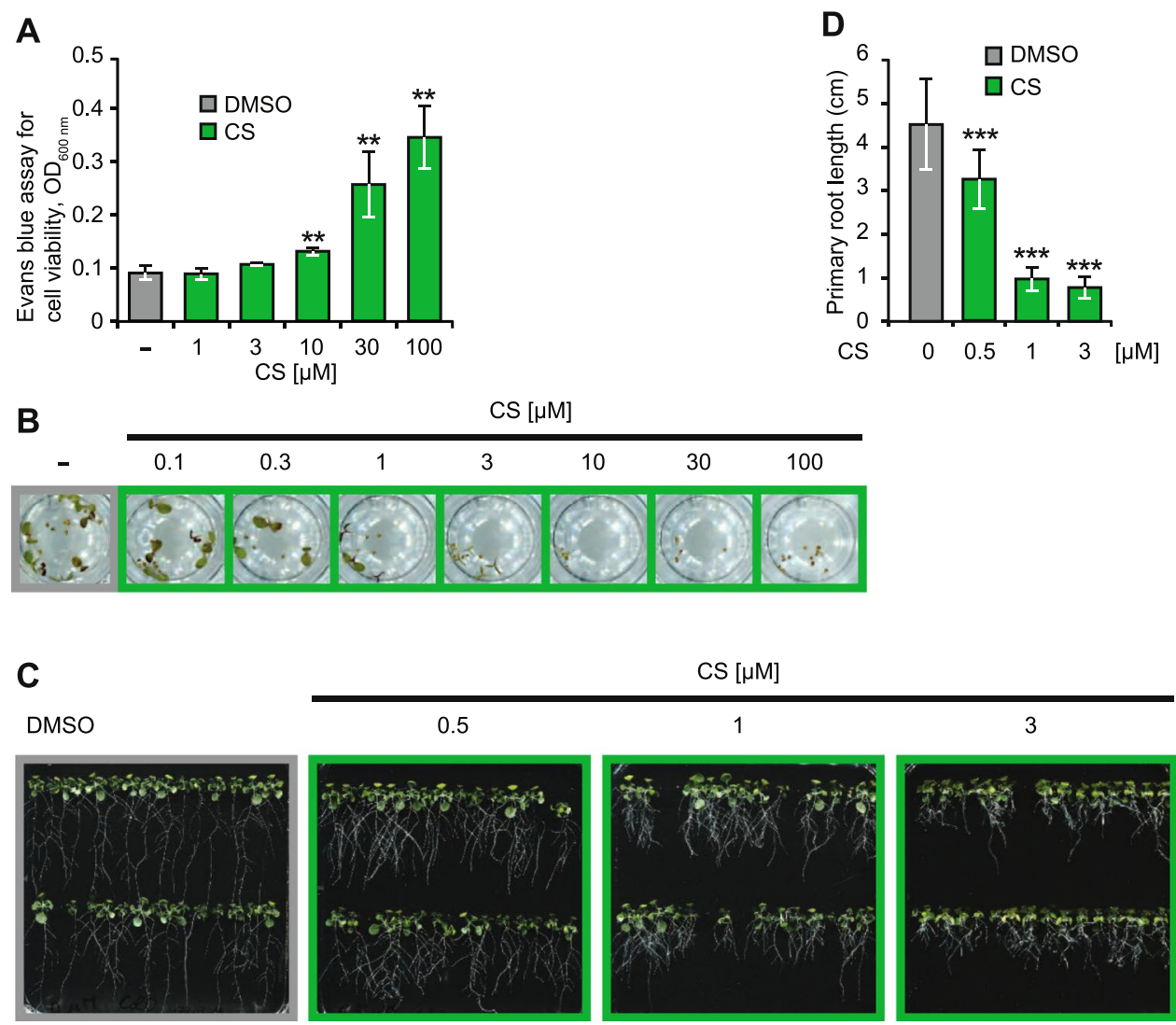

Figure 2. CS does not stress plants at its $\mathrm{EC}_{50}$ but affects seed germination and root growth. (A) 14-day-old Col-0 seedlings, treated with increasing concentrations of CS for $24 \mathrm{~h}$ were vacuum-infiltrated with Evans blue $(0.1 \%$, w/v) for $30 \mathrm{~min}$ and then kept for at least $6 \mathrm{~h}$ in the vacuum chamber. Dye bound to dead cells was quantified at $\mathrm{A}_{600} / \mathrm{A}_{680}$. (B) Properly sterilised and stratified Col-0 seeds were hydroponically grown for a week with the indicated CS concentration under long day conditions. (C) Properly sterilised Col-0 seeds were sown on solid half-MS phytagel media plates containing indicated concentrations of CS. Seeds on plates were stratified for $48 \mathrm{~h}$ and then kept vertically for 14 days in a long day growth chamber. (D) Root length of plants in (C) were quantified using the ImageJ software. At least 10 to 15 seedlings were used for root length calculation. All experiments were repeated at least twice with similar outputs. Asterisks indicate significant differences from respective controls $(* * \mathrm{P}<0.01$ and $* * * \mathrm{P}<0.001$, two-tailed Student's t-test).

(Supplemental Fig. S2). Overall, our results indicate that CS triggers plant immunity along with an impact on plant root growth.

CS' unique MoA induces PR1 independent of SA and SA-signalling components. Both natural and synthetic CLPs can trigger early or late defence responses such as ROS production and/or both SA and JA activation, respectively ${ }^{18-20,23,43-46}$. For compounds of the polymyxin class, in particular CS, we anticipated similar responses and, therefore, first tested its effect on three major phytohormonal signalling pathways: (i) JA-responsive VSP1p::GUS ${ }^{47}$, (ii) Auxin responsive DR5p::GUS ${ }^{48}$, and (iii) ABA responsive DC3p::GUS ${ }^{49}$. CS did not induce the reporter lines of JA, Auxin, and ABA, but SA-signalling thereby indicating its selectivity towards PR1 defence gene activation (Fig. 3A). Next, we tested effect of CS on ROS production, which is an excellent marker of stress induction upon CLPs application and is also known to trigger SA signalling. Col-0 seedlings treated with $5 \mu \mathrm{M}$ CS showed no induction of ROS production while flg22, the classical ROS inducer, caused a clear ROS burst (Fig. 3B). Nevertheless, to eliminate the possibility of a late ROS induction contributing to CS' bioactivity, we tested it on the ROS deficient $r b o h d / f$ mutant $^{50}$. Again, CS caused a strong induction of PR1 in both wild-type as well as the rbohd/f mutant (Supplemental Fig. S3). Similarly, another defence regulator, the MAPKs $\left(\mathrm{MPK} 6\right.$ and MPK3) ${ }^{51}$, were not induced by $\mathbf{C S}$ and no transient activation was noticed (Supplemental Fig. S4). Moreover, CS did not trigger sustained MAPK activation, a known pathway for SA-independent $P R 1$ activation $^{51}$, at later time points of 4,8 , and $24 \mathrm{~h}$, while flg22 triggered a transient MAPK activation (Fig. 3C). Our results suggest that CS-induced signalling works via a unique pathway independent of ROS and MAPK components.

PR1 is a canonical marker gene of SA and its expression is severely impaired in SA-signalling mutants ${ }^{52}$. To investigate whether CS requires SA or its associated components in Arabidopsis, we tested its response in mutants of (i) SA biosynthesis: sid2-1 $1^{4}$, (ii) SA-accumulation: $N a h G$ plant ${ }^{52}$, (iii) SA signalling regulation: $e d s 1-2^{5}$, and (iv) SA signalling transduction: $n p r 1-1^{53}$. Surprisingly, application of $5 \mu \mathrm{M}$ CS induced $P R 1$ expression in all genotypes whereas SA as expected failed to induce PR1 expression in $n p r 1-1^{54}$ and $N a h G$ plants ${ }^{55}$ (Fig. 3D). These 
A

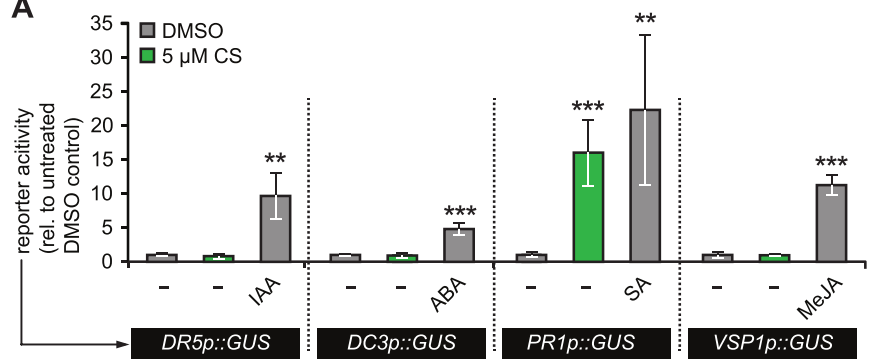

B

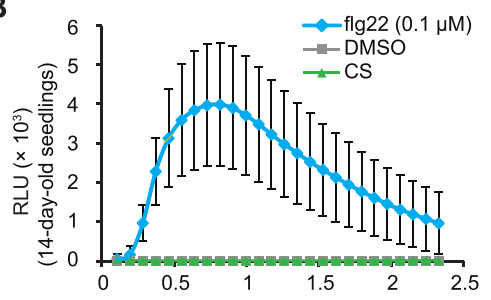

C

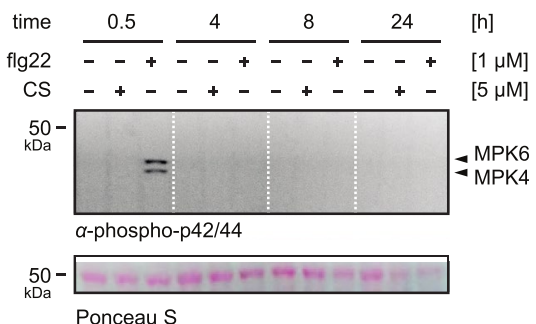

E

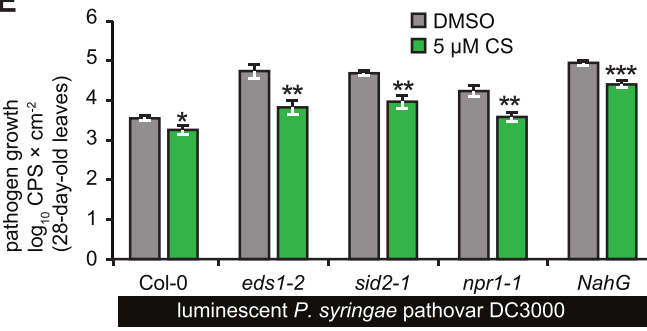

D

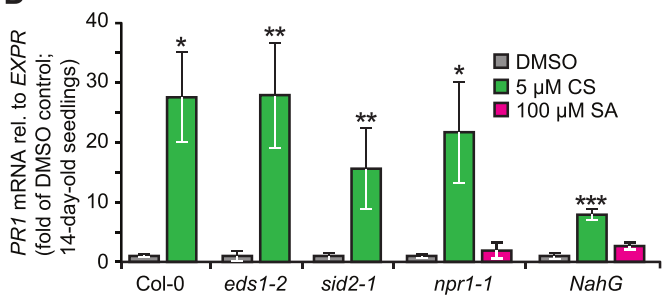

$\mathrm{F}$

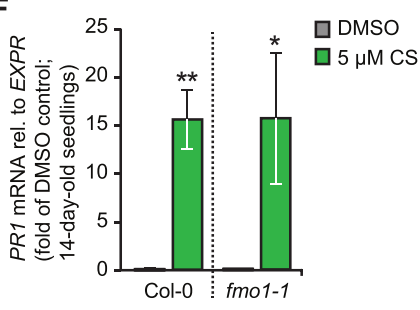

Figure 3. CS' unique MoA induces PR1 independent of SA and SA-signalling components. (A) 14-dayold GUS reporter seedlings, inducible by selective phytohormones, were treated either with CS $(5 \mu \mathrm{M})$ or with the respective inducers IAA $(5 \mu \mathrm{M}), \mathrm{ABA}(100 \mu \mathrm{M})$ or MeJA $(100 \mu \mathrm{M}))$ for $24 \mathrm{~h}$ in at least 3 biological replicates. GUS activity was normalised to the respective DMSO control of each reporter line. (B) 14-dayold Col-0 seedlings were treated with DMSO $(1 \%)$, CS $(5 \mu \mathrm{M})$, and flg22 $(0.1 \mu \mathrm{M})$ followed by immediate addition of luminol-peroxidase mix to detect chemiluminescence [(reported as relative light units (RLU)] by a luminometer for the indicated time course. The values represent the mean $( \pm S D$.) of at least 5-10 biological replicates. (C) Hydroponically grown Col-0 seedlings were treated with bacterial elicitor Flg22 ( $1 \mu \mathrm{M}), \mathbf{C S}$ $(5 \mu \mathrm{M})$ and DMSO $(1 \%)$ for indicated time durations before harvesting and detecting phosphorylated MPK6 and MPK 3 bands by immunoblotting using $\alpha$-phospho-p44/42. For the uncropped blot, see Supplemental Fig. S7. (D) Hydroponically grown, 14-day-old seedlings of indicated genotypes were treated with DMSO (1\%), CS $(5 \mu \mathrm{M})$ or SA $(100 \mu \mathrm{M})$ for $24 \mathrm{~h}$. PR1 gene levels were plotted as change fold to the respective DMSO controls of each genotype. The values represent the mean $( \pm \mathrm{SD})$ of at least three biological replicates. (E) Four-weekold leaves of different Arabidopsis genotypes were infiltrated with DMSO (1\%) or CS $(5 \mu \mathrm{M})$ for $24 \mathrm{~h}$ before spray-inoculating with a virulent luminescent luxCDABE-tagged Pst DC3000 strain (Fan et al., 2008). Pathogen growth was plotted as $\log _{10}$ CPS per $\mathrm{cm}^{2}$ relative to the DMSO control of each genotype. (F) 14-day-old Col-0 wild-type and fmo1-1 mutant seedlings were treated with DMSO (1\%) and CS (5 $\mu \mathrm{M})$ for $24 \mathrm{~h}$. PR1 transcripts were quantified via qRT-PCR and are reported relative to EXPR. The values represent the mean $( \pm \mathrm{SD})$ of at least three biological replicates. All experiments were repeated at least twice with similar outputs. Asterisks indicate significant differences from respective DMSO controls $(* \mathrm{P}<0.05$, $* * \mathrm{P}<0.01$, and $* * * \mathrm{P}<0.001$, two-tailed Student's t-test).

results, therefore, indicated a unique bioactivity of $\mathbf{C S}$ different from several well characterised $P R 1$ inducers ${ }^{11}$. Similar, albeit a slightly varying, bioactivity was observed in 28-days-old plants of same genotypes (Supplemental Fig. S5). We next tested whether CS induces plants' resistance to bacterial infection. We syringe-infiltrated leaves of 28-day-old wild-type as well as the SA-signalling and SA-deficient plants with or without $5 \mu \mathrm{M} \mathrm{CS}$ for $24 \mathrm{~h}$, before injecting the leaves with a luminescent luxCDABE-tagged Pst DC3000 strain ${ }^{56}$ for rapid and reliable quantification of bacterial growth. In accordance with the results from CS-triggered PR1 gene expression induction (Fig. 3D), CS application enhanced resistance in all tested Arabidopsis mutant genotypes (Fig. 3E).

We next sought out to find whether CS works via the SA-independent signalling branch. We tested the well-characterised fmo1-1 mutant defective in the FLAVIN-DEPENDENT MONOOXYGENASE1 (FMO1) protein regulating SA-independent resistance ${ }^{57}$. Surprisingly, CS triggered strong PR1 expression in fmo1-1 plants 

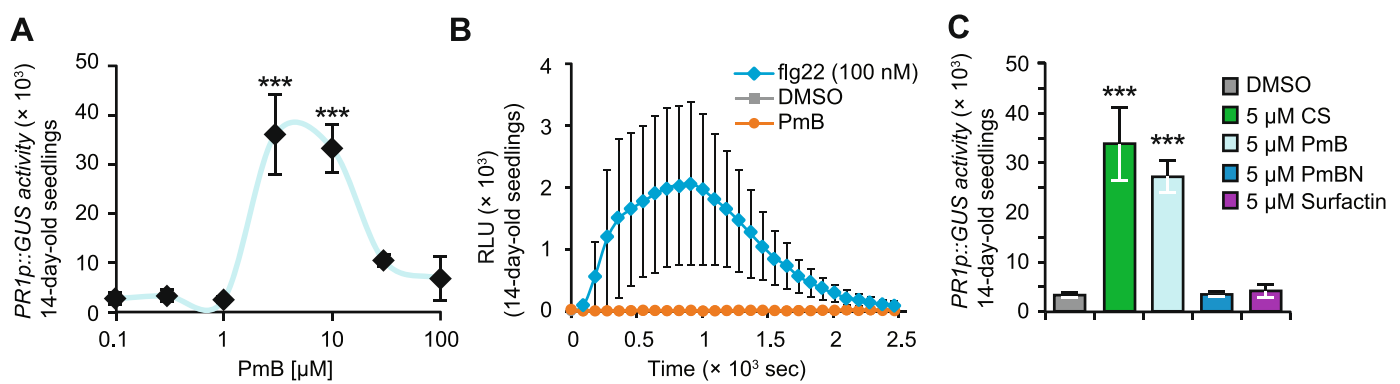

Figure 4. Structure-activity-relationship assays with CS. (A) 14-day-old hydroponically grown PR1p::GUS reporter seedlings were treated with increasing concentrations of $\mathrm{PmB}$ for $24 \mathrm{~h}$ before measuring GUS activity. (B) 14-day-old Col-0 seedlings were treated with DMSO (1\%), PmB $(5 \mu \mathrm{M})$, and flg22 $(0.1 \mu \mathrm{M})$ followed by immediate addition of luminol-peroxidase mix to detect chemiluminescence (reported as relative light units $(R L U))$ by a luminometer for the indicated time course. The values represent the mean $( \pm S D)$ of at least 5-10 biological replicates. (C) 14-day-old PR1p::GUS seedlings were treated with CS $(5 \mu \mathrm{M}), \mathrm{PmB}(5 \mu \mathrm{M}), \mathrm{PmBN}$ $(5 \mu \mathrm{M})$ and surfactin $(5 \mu \mathrm{M})$ for $24 \mathrm{~h}$ before quantifying GUS activity. The values represent the mean $( \pm S D)$ of at least 3 biological replicates. All experiments were repeated at least twice with similar outputs. Asterisks indicate significant differences from respective controls $(* * * \mathrm{P}<0.001$, two-tailed Student's t-test).

(Fig. 3F) akin to wild-type. In summary, our findings indicate CS-triggered $P R 1$ induction to be independent of both SA-dependent and SA-independent signalling factors and therefore occurs via an unconventional pathway.

Structure-activity-relationship assays with CS. To better understand the MoA of CS and its essential structural constituents, we tested some commercially available CS derivatives ${ }^{40}$. First, we tested PmB, an analogue with a D-phenyl alanine instead of D-leucine at ring position 6 of CS (Fig. 1A). Dose-response assays with PmB on PR1p::GUS displayed almost identical $\mathrm{EC}_{50}$ values of ca. $5 \mu \mathrm{M}$. Also, as observed with CS, PmB strongly reduced plant fitness at $30 \mu \mathrm{M}$ (Fig. 4A) and failed to induce ROS production (Fig. 4B). We thereby concluded that the close structural homolog PmB displays CS like bioactivities. Next, we focused on the two structural 'regions' of polymyxins critical for their bioactivity: the fatty acid chain ${ }^{58}$ and the pentacationic polypeptide fragment ${ }^{59}$. We tested Polymyxin B nonapeptide (PmBN), an enzymatically derived PmB derivative lacking the fatty acid chain ${ }^{60}$ and surfactin a well characterised CLP with different amino acid composition from $\mathbf{C S}^{18,23,44}$ (Fig. 1B). While CS and PmB strongly induced $P R 1 p:: G U S$ expression, $5 \mu \mathrm{M}$ of both PmBN and surfactin showed no agonistic effects (Fig. 4C). These results indicate that $\mathbf{C S}$ and PmB display a structure specific mode-of-action and the fatty acid chain is indispensable for its bioactivity.

CS functions via a stress-sensitive p38-like protein kinase pathway. The PCL is comprised of well-annotated compounds used already in different model systems $\mathrm{s}^{61-63}$ but plants. We reasoned the knowledge gained from previous PCL-based screens, and specifically with CS, could therefore be useful to unravel the molecular mechanisms of CS in plants. Notably, from a recent chemical genetic study with PCL on living C. elegans, CS was identified as a defence inducer functioning via an active p38 kinase signalling pathway ${ }^{29}$. We thus hypothesized CS might have similar mode-of-action in plants since the p38-like kinase pathway is known to exist in Arabidopsis ${ }^{35,36,64}$, wheat root cells ${ }^{65}$, and sweet potato ${ }^{66}$ in addition to other species such as algae ${ }^{67}$.

We began with a highly selective mammalian p38-kinase pathway inhibitor, SB203580 ${ }^{68}$, used frequently in plant studies ${ }^{35,36,65,66}$, to see whether it ablates CS' bioactivity? 14-day-old $P R 1 p:: G U S$ seedlings were pre-treated with 3-100 $\mu \mathrm{M} \mathrm{SB} 2035801 \mathrm{~h}$ before supplementing them with $5 \mu \mathrm{M}$ CS for $24 \mathrm{~h}$. Interestingly, application of SB203580 at $\geq 10 \mu \mathrm{M}$ significantly diminished CS' bioactivity (Fig. 5A). To avoid off-target effects at higher concentrations, we decided to use $10 \mu \mathrm{M}$ SB203580 for all future experiments. To confirm the observed reversal of CS' bioactivity by SB203580 is due to the interference of p38-like kinase pathway and not due to any off-target effect, we tested SB202474, an inactive SB203580 analogue having negligible effect on mammalian p38 kinase signalling ${ }^{69}$. SB202474 failed to suppress CS triggered PR1p::GUS activation indicating that the p38-like kinase pathway is indeed involved in $P R 1$ activation by CS. Finally, to test whether SA also requires the p38-like kinase, we tested $10 \mu \mathrm{M}$ of both SB203580 and SB202474 on SA treated PR1p::GUS seedlings. SB202474 showed no effect, but more remarkably SB203580 failed to reverse SA-triggered $P R 1$ activation (Fig. 5B).

The p38 kinase in a well-known membrane sensor shown to be rapidly phosphorylated upon application of CS in C.elegans ${ }^{29}$ and mice ${ }^{37}$. We, therefore, asked whether CS phosphorylates (i.e. activate) the p38-like kinase pathway in Arabidopsis? Taking advantage from our previous SAR studies, we treated 14-day-old Col-0 seedlings with $5 \mu \mathrm{M}$ of $\mathrm{CS}, \mathrm{PmB}, \mathrm{PmBN}$, and surfactin for $24 \mathrm{~h}$ before detecting the phosphorylation status via Western blots. Only CS and its close structural and functional analogue PmB, induced the phosphorylation of a protein in $\sim 46 \mathrm{kDa}$ detected by anti-phospho-p38 antibody (Fig. 5C). This protein band and antibody has been identified and used, respectively, in a number of reported studies ${ }^{36,65-67,70,71}$. Furthermore, in line with our previous findings in Fig. 4C, the functionally inactive CS derivative, PmBN, as well as the structurally divergent CLP, surfactin, did not trigger any phosphorylation (Fig. 5C). The inability of SB203580 to affect CS triggered phosphorylation was in accordance with previous reports demonstrating that SB203580 acts downstream of an activated p38 kinase pathway ${ }^{68}$. Collectively, our results present CS polymyxins as novel exogenous PR1 inducers in Arabidopsis working via an active p38-like kinase pathway. 

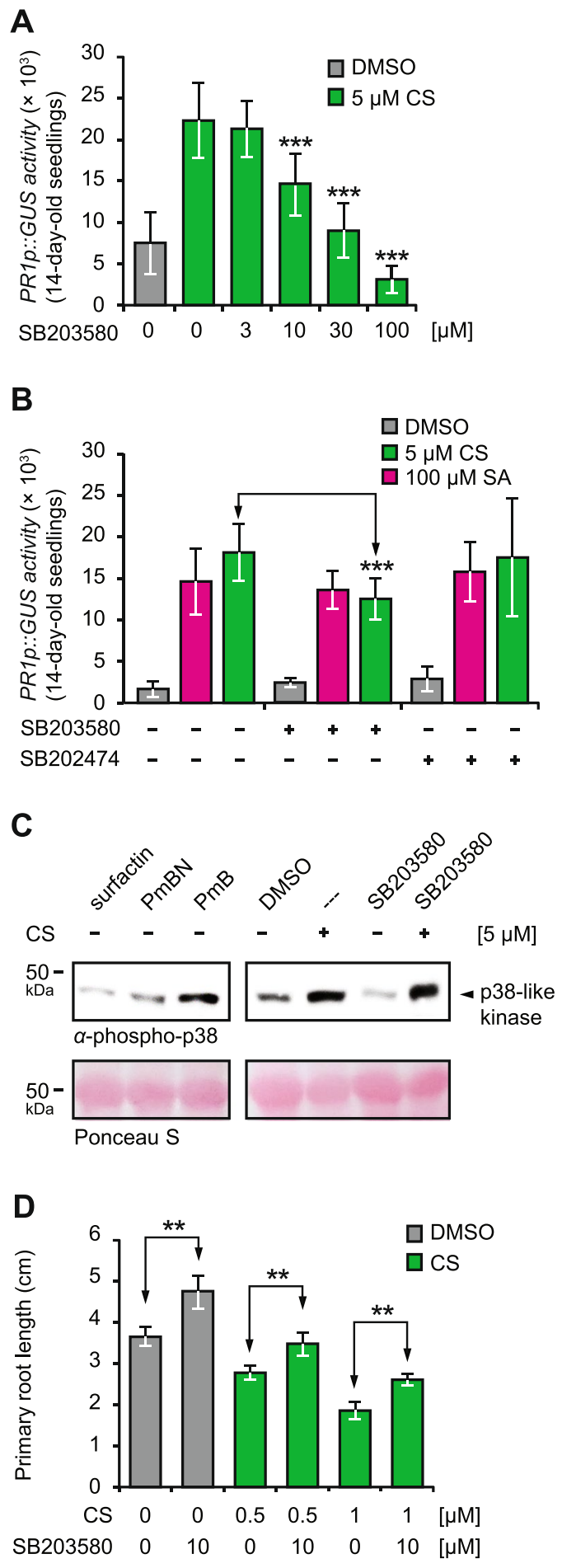

Figure 5. CS functions via a stress-sensitive p38-like protein kinase pathway. (A) 14-day-old PR1p::GUS reporter seedlings were pre-treated for $1 \mathrm{~h}$ with increasing concentrations of SB203580, followed by application of CS $(5 \mu \mathrm{M})$ for $24 \mathrm{~h}$ before measuring resulting GUS activity. (B) 14-day-old PR1p::GUS reporter seedlings were pretreated for $1 \mathrm{~h}$ with either SB203580 $(10 \mu \mathrm{M})$ or SB202474 $(10 \mu \mathrm{M})$ and were supplemented with CS $(5 \mu \mathrm{M})$ and SA $(100 \mu \mathrm{M})$ as indicated. (C) Western blot analysis of protein extracts from 14-day-old Col-0 wild-type seedlings treated with surfactin $(5 \mu \mathrm{M}), \operatorname{PmBN}(5 \mu \mathrm{M}), \operatorname{PmB}(5 \mu \mathrm{M}), \mathbf{C S}(5 \mu \mathrm{M})$, or DMSO $(1 \%)$ and the p38-like kinases inhibitor SB203580 $(10 \mu \mathrm{M})$ either alone or together with CS $(5 \mu \mathrm{M})$. Total protein was extracted and after gel electrophoresis and western blotting the membrane was probed with a commercially available $\alpha$-phospho p38 antibody. Equal protein loading is demonstrated by Ponceau S staining. For the uncropped blot, see Supplemental Fig. S8. (D) Properly sterilised Col-0 seeds were sown on solid half-MS phytagel media plates containing indicated concentrations of CS and $10 \mu \mathrm{M}$ SB203580. Root length were quantified using the ImageJ software. All experiments were repeated at least twice with similar outputs. Asterisks indicate significant differences from respective controls ( $* * * \mathrm{P}<0.001, * * \mathrm{P}<0.01$, two-tailed Student's t-test). 
Finally, application of SB203580 also reversed CS mediated primary root growth suppression (Fig. 5D), indicating it works via the p38-like kinase. Moreover, application of CS to tomato (Solanum lycopersicum cv. Moneymaker) leaf discs triggered significant $P R 1$ upregulation, likewise Arabidopsis, signifying it may have useful application in other plants (Supplemental Fig. S6).

\section{Discussion}

Using our well established in planta forward chemical genetic screening on whole Arabidopsis PR1p::GUS reporter seedlings ${ }^{39}$, we identified two polymyxins, $\mathbf{C S}$ and PmB, as a novel class of exogenous plant defence modulators and strong inducers of the canonical SA-marker gene, $P R 1$. Our mode-of-action experiments revealed that CS requires an active p38-like kinase signalling for its bioactivity. CS triggers the phosphorylation of a $46 \mathrm{kDa}$ protein that shares strong biochemical and immunological similarity to the mammalian p38 kinase. Strikingly, CS-triggered PR1 expression was independent of SA as well as classical SA-dependent and SA-independent signalling components. This is unlike many of the established exogenous SA functional mimics ${ }^{11}$ and CLPs ${ }^{21}$.

CS belongs to the polymyxin family of CLPs. These compounds are biosynthesised by PGPRs found as beneficial root dwellers in host plants ${ }^{72}$. The plant root microbiome, including many CLP producing PGPRs, has recently been recognised as a novel modulator of plant innate immunity ${ }^{73}$. Functionally, CS is a potent biosurfactant used as an antibacterial drug ${ }^{26,74}$. Besides its well-known antibacterial properties, CS was recently identified as an exogenous modulator of animal innate immunity ${ }^{29}$. Nevertheless, the plant immune-modulatory properties of CS, and in general polymyxins, were unknown before our study. This is in a stark contrast to the rich body of literature on the immunomodulatory roles of other well-characterized CLPs such as surfactin in Arabidopsis ${ }^{20,21,44}$. Our findings demonstrate that despite both CLP families enhance plant immunity they nevertheless feature different mode-of-actions. In Arabidopsis, CS treatment resulted in a strong upregulation of endogenous PR1 mRNA levels in both seedlings and mature plants. Furthermore, upregulation of PR1 expression took place in a dose-dependent manner with strong toxic effects ensuing at $30 \mu \mathrm{M}$ or higher. This was in accordance with the cell death assays which demonstrated CS-triggered toxicity at similar concentrations. Therefore, the cell death phenotypes at higher concentrations are most probably caused by the well-documented membrane disruption properties of CS. This effect was much pronounced in the seed germination and root growth assays where the plants were in constant exposure to $\mathbf{C S}$ for several days leading to the suppression of seed germination at $\geq 1 \mu \mathrm{M}$ or primary root growth inhibition at $\geq 0.5 \mu \mathrm{M}$.

Plant membranes are key players for plant immunity as they mark the first line of defence and their integrity is therefore carefully monitored and a change in membrane fluidity can induce stress leading to defence induc$\operatorname{tion}^{46,75}$. Activation of ROS and MAPKs are some of the early responses upon perception of MAMPs and CLPs at plasma membrane. Surprisingly, CS did not require any of the signalling components involved in ROS and MAPK signalling many of which are located in the plasma membrane, making it a unique inducer of plant defence. However, it is clear CS trigger transient membrane changes to trigger downstream responses. This model is supported by our SAR studies which demonstrated PmB, a close functional analogue of CS, also generates strong PR1 induction. In contrast, PmBN, a CS analogue without the membrane interacting lipid chain moiety and surfactin, a CLP with different amino acid and fatty acid chain length, failed to replicate CS like responses. These results suggest that membrane perturbation trigger is a result of some specific 'electrostatic' and lipid chain membrane interaction mediated by $\mathbf{C S}$ and the non-toxic concentration of $5 \mu \mathrm{M} \mathrm{CS}$ is too low to induce a complete collapse of membrane integrity but may cause membrane sensitisation. The low bioactive concentration of $5 \mu \mathrm{M} \mathrm{CS}$ in Arabidopsis is significantly lower than the high $50-100 \mu \mathrm{M}$ bioactive concentration range of $\operatorname{surfactin}^{76}$ and iturin $\mathrm{A}^{21}$ in Arabidopsis and other plant species.

A unique feature which sets CS apart from existing chemical and natural plant defence inducers is its ability to induce defence in SA-deficient plants as well as mutants of SA-dependent and SA-independent signalling components. Classical synthetic SA-mimics such as $\mathrm{BTH}^{77,78}$, Probenazole ${ }^{79}$, INA ${ }^{80}$, and N-cyanomethyl2-chloroisonicotinamide $(\mathrm{NCI})^{81}$ etc., require either or both SA and NPR1. CS, however, can induce PR1 expression in SA-deficient, sid2-1 and $N a h G$, plants as well as in the mutant of SA-signalling npr1-1 and the mutant of SA-regulation $e d s 1-2$. CLPs such as iturin A of the surfactin family cannot upregulate PR1 in an npr1-5 mutant background ${ }^{21}$. Thus, our data suggest that CS displays a unique MoA. Furthermore, the ability of CS to trigger PR1 induction can be seen translated in the Pst DC3000 infection assays where CS enhanced plant defence in all the tested SA and SA-signalling mutants. Since CS is a known biosurfactant, it is fair to assume it will have toxic effects on Pst DC3000 upon direct contact. In our studies we applied CS $24 \mathrm{~h}$ before pathogen application and also observed a varying growth of the bacteria across different mutant genotypes. Although we cannot completely rule out that the observed enhanced plant resistance vs. Pst DC3000 after CS treatment stems from its known antibiotic properties, the variance of bacterial growth in accordance with the mutant genotype indicates that CS also acts via modulation of plant defence signalling pathways.

The requirement of an active p38-like kinase pathway by $\mathbf{C S}$ to induce $P R 1$ expression is an intriguing discovery and is analogous to its bioactivity in C. elegans ${ }^{29}$. This also hints towards an evolutionary conserved role of this kinase in innate immunity. Even though, all known plant kinases lack the characteristic TGY (threonine-glycine-tyrosine) signature motif of animal p38 kinases ${ }^{32}$, many studies have strongly implicated the presence of a putative p38 homolog commonly called as "p38-like kinase". Currently, no genetic mutants are available to test the significance of p38-like kinase in plant physiology. To overcome this bottleneck, plant biologists have created conditional knockdowns by using a highly selective mammalian p38 kinase pathway inhibitor, SB203580 68 , and have validated the outputs by using its inactive variant SB202474 $4^{35,36}$. Similarly, scientists have routinely used the anti-phospho-p38-MAPK mammalian antibody to observe the activation of the p38-like kinase in plants such as sweet potato ${ }^{66}$, Arabidopsis ${ }^{35,36}$, perilla ${ }^{82}$, and wheat ${ }^{65}$ as well as in fungal species such as Dunaliella viridis ${ }^{83}$ or Dunaliella tertiolect ${ }^{70}$, and algae ${ }^{84}$. The anti-phospho-p38-MAPK antibody does not cross-react with phoshpo-ERK proteins of plants ${ }^{65}$ underlying its specificity toward the p38-like kinase. We 
performed similar experiments using SB203580 and demonstrated that it severely hampers CS-triggered PR1 induction. Remarkably, SB203580 did not inhibit SA-triggered PR1 induction suggesting SA pathway works independent of p38-like kinase in Arabidopsis. Next, using the anti-phospho-p38-MAPK antibody, we showed that both CS and its analogue $\mathrm{PmB}$ can induce the phosphorylation of a $46 \mathrm{kD}$ a protein kinase. Remarkably, surfactin, which is also a biosurfactant, and PmBN, an inactive CS derivative, could not trigger phosphorylation of the p38-like kinase. Another evidence of CS functioning via p38-like kinase was demonstrated by the root growth assay where SB203580 caused a significant reversion of CS induced root growth suppression. These results suggest a possible involvement of the p38-like kinase as a signalling juncture regulating growth and defence trade-off. However, further studies will be required to dissect this signalling branch. Nevertheless, our results suggest bioactivity of CS can well be a consequence of fine-tuned electrostatic interactions at the plant membrane or could also be transduced by a specific and yet unknown membrane-bound receptor leading to activation of the p38-like kinase pathway.

Overall, our results highlight an active p38-like kinase signalling pathway to be crucial for CS triggered PR1 activation and possibly root growth suppression. We show that polymyxins such as CS and PmB can trigger the activation of a $46 \mathrm{kD}$ a protein kinase pathway sharing significant biochemical and immunological similarity to mammalian p38 kinases. In future, compounds targeting p38-like kinase activity may find application as novel plant defence modulators.

\section{Materials and Methods}

Plant material. Transgenic fmo1- $1^{57}$, rbohd/ $f^{50}$, eds $1-2^{5}, n p r 1-1^{53}$, sid2- $1^{4}, N_{a h} G^{52}, P R 1 p:: G U S^{38}$, DC $3 p:: G U S^{49}$, DR5p::GUS ${ }^{48}$, and VSP1p::GUS ${ }^{47}$ in Arabidopsis thaliana (Col-0) background were used for various bioassays.

Growth conditions. Surface-sterilised seeds were sown in 96-well plates (PerkinElmer Inc., Germany) containing half-MS basal salt (Sigma Aldrich) liquid medium supplemented with $0.5 \%$ sucrose. Seeds were stratified at $4{ }^{\circ} \mathrm{C}$ in the dark for 48 hours and later grown for 14 days under long day conditions (day/night cycle of $16 / 8 \mathrm{~h}$ at $21 / 19^{\circ} \mathrm{C}$ ). For soil grown Col-0, sid2-1, npr1-1, eds1-2, and NahG plants, seeds were sown directly on soil and stratified at $4^{\circ} \mathrm{C}$ in the dark for $48 \mathrm{~h}$. Plants were grown for about 28 days under long day conditions before performing biological assays.

Chemicals. The tested chemicals were taken from the Prestwick Chemical Library (1280 compounds, Illkirch-Graffenstaden, France) in addition to a collection of 128 handpicked compounds. CS was purchased from AK Scientific (San Francisco, USA), surfactin and PmB were obtained from Santa Cruz Biotechnology (Dallas, USA), PmBN and SB203580 from Sigma (Deisenhofen, Germany), and SB202474 from Cayman chemicals (Michigan, United States).

Activator screen using PR1p::GUS reporter. Screening was performed as described ${ }^{39}$. In brief, 14-day-old Arabidopsis seedlings harbouring the PR1p::GUS reporter were pre-treated with chemicals (dissolved in DMSO) at a final concentration of $20 \mu \mathrm{M}$ for $24 \mathrm{~h}$. Seedlings treated with $200 \mu \mathrm{M}$ SA (dissolved in DMSO) or solvent DMSO (1\%) served as internal controls. For each plant, at least two biological replicates were performed, and the resulting activity was normalised to control DMSO samples located on the same microplate.

in situ GUS activity quantification. The assay was performed as described previously ${ }^{39}$. In brief, 14-day-old seedlings grown in 96-well microplates were submerged in $150 \mu \mathrm{L}$ lysis buffer $(50 \mathrm{mM}$ sodium phosphate, $\mathrm{pH} 7.0,10 \mathrm{mM}$ EDTA, $0.1 \%$ Triton X-100), containing $1 \mathrm{mM} \mathrm{4-MUG}$, at $37^{\circ} \mathrm{C}$ for $90 \mathrm{~min}$. At the end of the incubation period, $50 \mu \mathrm{L} 1 \mathrm{M} \mathrm{Na}_{2} \mathrm{CO}_{3}$ (stop solution) was added to each well and the resulting 4-MU fluorescence was directly determined in a microplate reader as described before (excitation/emission wavelength of $365 / 455 \mathrm{~nm}$ ). Activity was directly expressed as relative light units (RLU per seedling).

Root length quantification. Solid half-strength MS medium was supplemented with MES $\left(0.5 \mathrm{~g} \mathrm{~L}^{-1}\right)$, sucrose $\left(5 \mathrm{gL}^{-1}\right)$, and $0.8 \%(\mathrm{w} / \mathrm{v})$ Phytagel (Sigma Aldrich). Media was autoclaved and chemicals were added to media at $60^{\circ} \mathrm{C}$. Seeds were sown directly on the plates, stratified for $48 \mathrm{~h}$, and grown for two-weeks under long day conditions. Images were taken and quantified using Image J software (https://imagej.nih.gov/ij/).

Oxidative burst assay. Luminol-based oxidative burst measurement was performed with 10-day-old Col-0 seedlings in 96-well white microplates. Seedlings were submerged in $100 \mu \mathrm{L} \mathrm{H}_{2} \mathrm{O}$ supplemented with $5 \mu \mathrm{M} \mathrm{CS}$, $1 \%$ DMSO or $0.1 \mu \mathrm{M}$ flg22. Luminescence detection was started immediately in a luminometer (Centro LB960, Berthold Technologies, Germany) by adding $100 \mu \mathrm{M}$ luminol (L-012 from Wako Chemicals, USA) and $10 \mu \mathrm{g} \mathrm{mL} \mathrm{m}^{-1}$ horseradish peroxidase (Sigma-Aldrich, P6782) to the wells. Luminescence was measured every minute for the next 30 minutes. At least 5-10 biological replicates were used for each measurement.

Immunoblotting assays. Immunoblotting of MAPK as $\mathrm{per}^{51}$ and $\mathrm{p} 38$-like kinase as per ${ }^{36}$ was done with minor modifications. In brief, total protein was extracted from chemically-treated 14-day-old Arabidopsis Col-0 seedlings and $10 \mu \mathrm{g}$ equal protein amounts were separated in $10 \%$ polyacrylamide gel by SDS-PAGE. For western blot, the gel was transferred to nitrocellulose membranes and probed with primary antibodies overnight at $4{ }^{\circ} \mathrm{C}$. MAPK was detected using anti-phospho-p44/p42 MAPK antibodies (Cell Signalling Technology, 9102) while for p38-like kinase an anti-phospho p38-MAPK (Cell Signalling Technology, 9211) was used. Horseradish peroxidase-tagged goat anti-rabbit secondary antibodies were employed in both cases. Phosphorylation was detected using the Pierce ECL Western Blotting Substrate (Thermo Scientific, Rockford, USA) and imaged via ImageQuant LAS 4000 (GE Healthcare Life Sciences, Sweden). 
Cell death assay using Evans blue dye. Cell death was examined by Evans blue staining as per ${ }^{85}$ with minor modifications. Briefly, 14-day-old Col-0 seedlings were vacuum-infiltrated in Evans blue (0.1\% w/v) for $30 \mathrm{~min}$ and then maintained for at least $6 \mathrm{~h}$ in the vacuum chamber. To remove unbound dye post staining, extensive washing with autoclaved water was done. Dye bound to dead cells was solubilised in methanol (50\% v/v) and SDS (1\%) for 30 min on a shaker and quantified in a spectrophotometer at $A_{600} / A_{680}$.

Quantitative real-time PCR analysis. Total plant RNA was extracted using the manufacturer's protocol (Bio-Budget technologies GmbH, Germany) and was used to make first strand CDNA using SuperScript ${ }^{\mathrm{TM}}$ II Reverse Transcriptase (Invitrogen). The cDNA was used as template in PCR reactions using gene specific primers (Sigma, Germany) and $\mathrm{iQ}^{\mathrm{TM}}$ SYBR $^{\circledR}$ Green Supermix (Bio-Rad, Germany) on an iQ5 Real-Time PCR Detection System (Bio-Rad, Germany). The experiment was performed in three biological replicates (with one technical replicate for each biological replicate). The following primers $\left(5^{\prime}-3^{\prime}\right)$ were used in our study:

\section{Primers for arabidopsis. AtEXPR (reference gene) FP: GAGCTGAAGTGGCTTCCATGAC AtEXPR RP: GGTCCGACATACCCATGATCC \\ AtPR1 FP: TCACAACCAGGCACGAGGAG \\ AtPR1 RP: CACCGCTACCCCAGGCTAAG \\ Primers for Tomato. SlHKG4 (reference gene) FP: GCTCCAGAAAGCTACATC SlHKG4 RP: CGTCTCCTATAACGACTC \\ SlPR1 FP: CCGTGCAATTGTGGGTGTC SIPR1 RP: GAGTTGCGCCAGACTACTTGAGT}

Statistical analyses. Z-score analyses for the primary quantitative screening was done as per ${ }^{86}$. All statistical analyses done elsewhere were performed in Excel spreadsheets.

\section{References}

1. Boller, T. \& Felix, G. A renaissance of elicitors: perception of microbe-associated molecular patterns and danger signals by patternrecognition receptors. Annu. Rev. Plant Biol. 60, 379-406 (2009).

2. Dodds, P. N. \& Rathjen, J. P. Plant immunity: towards an integrated view of plant-pathogen interactions. Nat. Rev. Genet. 11, 539-548 (2010).

3. Klessig, D. F., Choi, H. W. \& Dempsey, D. A. Systemic Acquired Resistance and Salicylic Acid: Past, Present, and Future. Mol. PlantMicrobe Interact. 31, 871-888 (2018).

4. Wildermuth, M. C., Dewdney, J., Wu, G. \& Ausubel, F. M. Isochorismate synthase is required to synthesize salicylic acid for plant defence. Nature 414, 562-565 (2001).

5. Parker, J. E. et al. Characterization of eds1, a mutation in Arabidopsis suppressing resistance to Peronospora parasitica specified by several different RPP genes. Plant Cell 8, 2033-2046 (1996).

6. Wu, Y. et al. The Arabidopsis NPR1 Protein Is a Receptor for the Plant Defense Hormone Salicylic Acid. Cell Rep. 1, 639-647 (2012).

7. Fu, Z. Q. et al. NPR3 and NPR4 are receptors for the immune signal salicylic acid in plants. Nature 486, 228-232 (2012).

8. Kuai, X., Barraco, C. \& Després, C. Combining Fungicides and Prospective NPR1-Based "Just-in-Time" Immunomodulating Chemistries for Crop Protection. Front. Plant Sci. 8, 1715 (2017).

9. Dejonghe, W. \& Russinova, E. Plant Chemical Genetics: From Phenotype-Based Screens to Synthetic Biology. Plant Physiol. 174, 5-20 (2017).

10. Hicks, G. R. \& Raikhel, N. V. Small molecules present large opportunities in plant biology. Annu. Rev. Plant Biol. 63, 261-82 (2012).

11. Bektas, Y. \& Eulgem, T. Synthetic Plant Defense Elicitors. Front. Plant Sci. 5, 804 (2015).

12. Friedrich, L. et al. A benzothiadiazole derivative induces systemic acquired resistance in tobacco. Plant J. 10, 61-70 (1996).

13. Uknes, S. et al. Acquired resistance in Arabidopsis. Plant Cell 4, 645-656 (1992).

14. Knoth, C., Salus, M. S., Girke, T. \& Eulgem, T. The synthetic elicitor 3,5-dichloroanthranilic acid induces NPR1-dependent and NPR1-independent mechanisms of disease resistance in Arabidopsis. Plant Physiol. 150, 333-347 (2009).

15. Watanabe, T. I. et al. The characteristics of probenazole (oryzemate) for the control of rice blasts. J. Pest. Sci 2, 291-296 (1977)

16. Noutoshi, Y., Ikeda, M., Saito, T., Osada, H. \& Shirasu, K. Sulfonamides identified as plant immune-priming compounds in highthroughput chemical screening increase disease resistance in Arabidopsis thaliana. Front. Plant Sci. 3, 245 (2012).

17. Schneider, T., Muller, A., Miess, H. \& Gross, H. Cyclic lipopeptides as antibacterial agents - potent antibiotic activity mediated by intriguing mode of actions. Int. J. Med. Microbiol. 304, 37-43 (2014).

18. Ongena, M. et al. Surfactin and fengycin lipopeptides of Bacillus subtilis as elicitors of induced systemic resistance in plants. Environ. Microbiol. 9, 1084-1090 (2007).

19. Farace, G. et al. Cyclic lipopeptides from Bacillus subtilis activate distinct patterns of defence responses in grapevine. Mol. Plant Pathol. 16, 177-187 (2015).

20. Jourdan, E. et al. Insights into the defense-related events occurring in plant cells following perception of surfactin-type lipopeptide from Bacillus subtilis. Mol. Plant. Microbe. Interact. 22, 456-468 (2009).

21. Kawagoe, Y. et al. Cyclic lipopeptide iturin A structure-dependently induces defense response in Arabidopsis plants by activating SA and JA signaling pathways. Biochem. Biophys. Res. Commun. 460, 1015-1020 (2015).

22. Ongena, M. \& Jacques, P. Bacillus lipopeptides: versatile weapons for plant disease biocontrol. Trends Microbiol. 16, 115-125 (2008).

23. Henry, G., Deleu, M., Jourdan, E., Thonart, P. \& Ongena, M. The bacterial lipopeptide surfactin targets the lipid fraction of the plant plasma membrane to trigger immune-related defence responses. Cell. Microbiol. 13, 1824-1837 (2011).

24. Lal, S. \& Tabacchioni, S. Ecology and biotechnological potential of Paenibacillus polymyxa: a minireview. Ind. J. Microbiol. 49, 2-10 (2009).

25. Vaara, M. Polymyxins and their novel derivatives. Curr. Opin. Microbiol. 13, 574-581 (2010).

26. Biswas, S., Brunel, J. M., Dubus, J. C., Reynaud-Gaubert, M. \& Rolain, J. M. Colistin: An update on the antibiotic of the 21st century. Expert Rev. Anti-Infective Ther. 10, 917-934 (2012).

27. Minagawa, S., Kondoh, Y., Sueoka, K., Osada, H. \& Nakamoto, H. Cyclic lipopeptide antibiotics bind to the N-terminal domain of the prokaryotic Hsp90 to inhibit the chaperone activity. Biochem. J. 435, 237-246 (2011).

28. Zininga, T. et al. Polymyxin B inhibits the chaperone activity of Plasmodium falciparum Hsp70. Cell Stress Chaperones 22, 707-715 (2017).

29. Cai, Y., Cao, X. \& Aballay, A. Whole-Animal Chemical Screen Identifies Colistin as a New Immunomodulator That Targets Conserved Pathways. MBio 5 (2014) 
30. Maeda, T., Wurgler-Murphy, S. M. \& Saito, H. A two-component system that regulates an osmosensing MAP kinase cascade in yeast. Nature 369, 242-245 (1994).

31. Kim, H. S. \& Lee, M. S. Essential role of STAT1 in caspase-independent cell death of activated macrophages through the p38 mitogen-activated protein kinase/STAT1/reactive oxygen species pathway. Mol. Cell Biol. 25, 6821-6833 (2005).

32. Rodriguez, M. C., Petersen, M. \& Mundy, J. Mitogen-activated protein kinase signaling in plants. Annu. Rev. Plant Biol. 61, 621-649 (2010).

33. Munnik, T. et al. Distinct osmo-sensing protein kinase pathways are involved in signalling moderate and severe hyper-osmotic stress. Plant J. 20, 381-388 (1999).

34. Popping, B., Gibbons, T. \& Watson, M. D. The Pisum sativum MAP kinase homologue (PsMAPK) rescues the Saccharomyces cerevisiae hogl deletion mutant under conditions of high osmotic stress. Plant Mol. Biol. 31, 355-363 (1996).

35. Jiang, J., Wang, P., An, G., Wang, P. \& Song, C. P. The involvement of a P38-like MAP kinase in ABA-induced and $\mathrm{H}_{2} \mathrm{O}_{2}$-mediated stomatal closure in Vicia faba L. Plant Cell Rep. 27, 377-385 (2008).

36. Livanos, P., Galatis, B., Gaitanaki, C. \& Apostolakos, P. Phosphorylation of a p38-like MAPK is involved in sensing cellular redox state and drives atypical tubulin polymer assembly in angiosperms. Plant Cell Environ. 37, 1130-1143 (2014).

37. Dai, C., Li, J., Tang, S., Li, J. \& Xiao, X. Colistin-induced nephrotoxicity in mice involves the mitochondrial, death receptor, and endoplasmic reticulum pathways. Antimicrob. Agents Chemother. 58, 4075-4085 (2014).

38. Shapiro, A. D. \& Zhang, C. The role of NDR1 in avirulence gene-directed signaling and control of programmed cell death in Arabidopsis. Plant Physiol. 127, 1089-1101 (2001).

39. Halder, V. \& Kombrink, E. Facile high-throughput forward chemical genetic screening by in situ monitoring of glucuronidase-based reporter gene expression in Arabidopsis thaliana. Front. Plant Sci. 6, 13 (2015).

40. Velkov, T., Thompson, P. E., Nation, R. L. \& Li, J. Structure-Activity Relationships of Polymyxin Antibiotics. J. Med. Chem. 53, 1898-1916 (2010).

41. Clissold, S. P. Aspirin and Related Derivatives of Salicylic Acid. Drugs 32, 8-26 (1986).

42. Hong, C. E., Kwon, S. Y. \& Park, J. M. Biocontrol activity of Paenibacillus polymyxa AC-1 against Pseudomonas syringae and its interaction with Arabidopsis thaliana. Microbiol. Res. 185, 13-21 (2016).

43. Brotman, Y., Makovitzki, A., Shai, Y., Chet, I. \& Viterbo, A. Synthetic ultrashort cationic lipopeptides induce systemic plant defense responses against bacterial and fungal pathogens. Appl. Environ. Microbiol. 75, 5373-5379 (2009).

44. Cawoy, H. et al. Plant defense stimulation by natural isolates of bacillus depends on efficient surfactin production. Mol. Plant. Microbe. Interact. 27, 87-100 (2014).

45. Varnier, A. L. et al. Bacterial rhamnolipids are novel MAMPs conferring resistance to Botrytis cinerea in grapevine. Plant Cell Env. 32, 178-193 (2009).

46. Luzuriaga-Loaiza, W. P. et al. Synthetic Rhamnolipid Bolaforms trigger an innate immune response in Arabidopsis thaliana. Sci. Rep. 8 (2018).

47. Zheng, W. et al. Bestatin, an inhibitor of aminopeptidases, provides a chemical genetics approach to dissect jasmonate signaling in Arabidopsis. Plant Physiol 141, 1400-1413 (2006).

48. Ulmasov, T., Murfett, J., Hagen, G. \& Guilfoyle, T. J. Aux/IAA proteins repress expression of reporter genes containing natural and highly active synthetic auxin response elements. Plant Cell 9, 1963-1971 (1997).

49. Chak, R. K., Thomas, T. L., Quatrano, R. S. \& Rock, C. D. The genes ABI1 and ABI2 are involved in abscisic acid- and droughtinducible expression of the Daucus carota L. Dc3 promoter in guard cells of transgenic Arabidopsis thaliana (L.) Heynh. Planta 210, $875-883(2000)$

50. Torres, M. A., Dangl, J. L. \& Jones, J. D. G. Arabidopsis gp91phox homologues AtrbohD and AtrbohF are required for accumulation of reactive oxygen intermediates in the plant defense response. Proc. Natl. Acad. Sci. 99, 517-522 (2002).

51. Tsuda, K. et al. Dual Regulation of Gene Expression Mediated by Extended MAPK Activation and Salicylic Acid Contributes to Robust Innate Immunity in Arabidopsis thaliana. PLoS Genet. 9, e1004015 (2013).

52. Delaney, T. P. et al. A Central Role of Salicylic Acid in Plant Disease Resistance. Science 266, 1247-1250 (1994).

53. Cao, H., Bowling, S. A., Gordon, A. S. \& Dong, X. N. Characterization of an Arabidopsis Mutant That Is Nonresponsive to Inducers of Systemic Acquired-Resistance. Plant Cell 6, 1583-1592 (1994).

54. Cao, H., Glazebrook, J., Clarke, J. D., Volko, S. \& Dong, X. The Arabidopsis NPR1 gene that controls systemic acquired resistance encodes a novel protein containing ankyrin repeats. Cell 88, 57-63 (1997).

55. Nagashima, Y., Iwata, Y., Ashida, M., Mishiba, K. I. \& Koizumi, N. Exogenous salicylic acid activates two signaling arms of the unfolded protein response in arabidopsis. Plant Cell Physiol. 55, 1772-1778 (2014).

56. Fan, J., Crooks, C. \& Lamb, C. High-throughput quantitative luminescence assay of the growth in planta of Pseudomonas syringae chromosomally tagged with Photorhabdus luminescens luxCDABE. Plant J. 53, 393-399 (2008).

57. Bartsch, M. et al. Salicylic acid-independent ENHANCED DISEASE SUSCEPTIBILITY1 signaling in Arabidopsis immunity and cell death is regulated by the monooxygenase FMO1 and the Nudix hydrolase NUDT7. Plant Cell 18, 1038-1051 (2006).

58. Sakura, N. et al. The contribution of the N-terminal structure of polymyxin B peptides to antimicrobial and lipopolysaccharide binding activity. Bull. Chem. Soc. Jpn. 77, 1915-1924 (2004).

59. Viljanen, P. \& Vaara, M. Susceptibility of Gram-Negative Bacteria to Polymyxin-B Nonapeptide. Antimicrob. Agents Chemother. 25, 701-705 (1984).

60. Delcour, A. H. Outer membrane permeability and antibiotic resistance. Biochim. Biophys. Acta 1794, 808-816 (2009).

61. Dorfmueller, H. C. \& van Aalten, D. M. F. Screening-based discovery of drug-like O-GlcNAcase inhibitor scaffolds. FEBS Lett. 584, 694-700 (2010).

62. Siles, S. A., Srinivasan, A., Pierce, C. G., Lopez-Ribot, J. L. \& Ramasubramanian, A. K. High-throughput screening of a collection of known pharmacologically active small compounds for identification of candida albicans biofilm inhibitors. Antimicrob. Agents Chemother. 57, 3681-3687 (2013).

63. Tkachyova, I. et al. NDST1 preferred promoter confirmation and identification of corresponding transcriptional inhibitors as substrate reduction agents for multiple mucopolysaccharidosis disorders. PLoS One 11, e0162145 (2016).

64. Capone, R., Tiwari, B. S. \& Levine, A. Rapid transmission of oxidative and nitrosative stress signals from roots to shoots in Arabidopsis. Plant Physiol. Biochem. 42, 425-428 (2004).

65. Komis, G., Apostolakos, P., Gaitanaki, C. \& Galatis, B. Hyperosmotically induced accumulation of a phosphorylated p38-like MAPK involved in protoplast volume regulation of plasmolyzed wheat root cells. FEBS Lett. 573, 168-174 (2004).

66. Lin, H.-H. et al. The p38-like MAP kinase modulated $\mathrm{H}_{2} \mathrm{O}_{2}$ accumulation in wounding signaling pathways of sweet potato. Plant Sci. 280, 305-313 (2019).

67. Gasulla, F. et al. The role of phospholipase D and MAPK signaling cascades in the adaption of lichen microalgae to desiccation: Changes in membrane lipids and phosphoproteome. Plant Cell Physiol. 57, 1908-1920 (2016).

68. Kumar, S., Jiang, M. S., Adams, J. L. \& Lee, J. C. Pyridinylimidazole compound SB 203580 inhibits the activity but not the activation of p38 mitogen-activated protein kinase. Biochem. Biophys. Res. Commun. 263, 825-831 (1999).

69. Lee, J. C. et al. A protein kinase involved in the regulation of inflammatory cytokine biosynthesis. Nature 372, 739-746 (1994).

70. García-Gómez, C. et al. Cell survival after UV radiation stress in the unicellular chlorophyte Dunaliella tertiolecta is mediated by DNA repair and MAPK phosphorylation. J. Exp. Bot. 63, 5259-5274 (2012). 
71. Jiang, J. \& Song, C. P. MEK1/2 and p38-like MAP kinase successively mediate $\mathrm{H}(2) \mathrm{O}(2)$ signaling in Vicia guard cell. Plant Signal. Behav. 3, 996-998 (2008).

72. Vacheron, J. et al. Plant growth-promoting rhizobacteria and root system functioning. Front. Plant Sci. 4, 356 (2013).

73. Hacquard, S., Spaepen, S., Garrido-Oter, R. \& Schulze-Lefert, P. Interplay Between Innate Immunity and the Plant Microbiota. Annu. Rev. Phytopathol. 55, 565-589 (2017).

74. Kadar, B., Kocsis, B., Nagy, K. \& Szabo, D. The renaissance of polymyxins. Curr. Med. Chem. 20, 3759-3773 (2013).

75. Jung, S. J., Lee, H. G. \& Seo, P. J. Membrane-triggered plant immunity. Plant Signal. Behav. 9, e29729 (2014).

76. Bais, H. P., Ray, F. \& V., J. M. Biocontrol of Bacillus subtilis against Infection of Arabidopsis Roots by Pseudomonas syringae Is Facilitated by Biofilm Formation and Surfactin Production. Plant Physiol. 134, 307-319 (2004).

77. Lawton, K. A. et al. Benzothiadiazole induces disease resistance in Arabidopsis by activation of the systemic acquired resistance signal transduction pathway. Plant J. 10, 71-82 (1996).

78. Kohler, A., Schwindling, S. \& Conrath, U. Benzothiadiazole-Induced Priming for Potentiated Responses to Pathogen Infection, Wounding, and Infiltration of Water into Leaves Requires the NPR1/NIM1 Gene in Arabidopsis. Plant Physiol. 128, 1046-1056 (2002).

79. Yoshioka, K., Nakashita, H., Klessig, D. F. \& Yamaguchi, I. Probenazole induces systemic acquired resistance in Arabidopsis with a novel type of action. Plant J. 25, 149-157 (2001)

80. Delaney, T. P., Friedrich, L. \& Ryals, J. A. Arabidopsis signal transduction mutant defective in chemically and biologically induced disease resistance. Proc. Natl. Acad. Sci. 92, 6602-6 (1995).

81. Yasuda, M. et al. N-cyanomethyl-2-chloroisonicotinamide induces systemic acquired resistance in Arabidopsis without salicylic acid accumulation. Biosci. Biotechnol. Biochem. 67, 322-328 (2003).

82. Izumi, Y. et al. Isolation, identification, and biological evaluation of Nrf2-ARE activator from the leaves of green perilla (Perilla frutescens var. crispa f. viridis). Free Radic. Biol. Med. 53, 669-679 (2012).

83. Jiménez, C., Berl, T., Rivard, C. J., Edelstein, C. L. \& Capasso, J. M. Phosphorylation of MAP kinase-like proteins mediate the response of the halotolerant alga Dunaliella viridis to hypertonic shock. Biochim. Biophys. Acta - Mol. Cell Res. 1644, 61-69 (2004).

84. Parages, M. L., Capasso, J. M., Niell, F. X. \& Jiménez, C. Responses of cyclic phosphorylation of MAPK-like proteins in intertidal macroalgae after environmental stress. J. Plant Physiol. 171, 276-284 (2014).

85. Shi, L. et al. Involvement of sphingoid bases in mediating reactive oxygen intermediate production and programmed cell death in Arabidopsis. Cell Res. 17, 1030-1040 (2007).

86. Malo, N., Hanley, J. A., Cerquozzi, S., Pelletier, J. \& Nadon, R. Statistical practice in high-throughput screening data analysis. Nat. Biotechnol. 24, 167-175 (2006).

\section{Acknowledgements}

We thank Brigitte Pickle for excellent technical assistance and Erich Kombrink for discussions. The work was funded by the University of Duisburg-Essen and a long term DAAD fellowship (A/10/74508).

\section{Author Contributions}

V.H. designed the study, performed all experiments, and analysed the data. M.N.S.S. performed the tomato experiment. F.K. helped with figures and text. V.H. and M.K. wrote the main manuscript text.

\section{Additional Information}

Supplementary information accompanies this paper at https://doi.org/10.1038/s41598-019-47526-5.

Competing Interests: The authors declare no competing interests.

Publisher's note: Springer Nature remains neutral with regard to jurisdictional claims in published maps and institutional affiliations.

(c) (i) Open Access This article is licensed under a Creative Commons Attribution 4.0 International License, which permits use, sharing, adaptation, distribution and reproduction in any medium or format, as long as you give appropriate credit to the original author(s) and the source, provide a link to the Creative Commons license, and indicate if changes were made. The images or other third party material in this article are included in the article's Creative Commons license, unless indicated otherwise in a credit line to the material. If material is not included in the article's Creative Commons license and your intended use is not permitted by statutory regulation or exceeds the permitted use, you will need to obtain permission directly from the copyright holder. To view a copy of this license, visit http://creativecommons.org/licenses/by/4.0/.

(C) The Author(s) 2019 